\title{
Empirical Analysis on the USD/all Exchange Rate Volatility in Albanian Market: Preliminary Results
}

\author{
Ardita Todri \\ Corresponding author: Lecturer in Finance \& Accounting Department. Faculty of Economics, University of Elbasan. "L.D.H. Myzyri",
} Pall. Nr 10, H3/C, Elbasan (3001) Albania. ardita.todri@uniel.edu.al

Giuseppe Di Liddo

Lecturer in Economics. DISAG/University of Bari. Largo Abbazia Santa Scolastica 53, 1st floor, room 7. Bari - Italy. giudiliddo@hotmail.com

\begin{abstract}
This paper aims to forecast the USD/ALL exchange rate volatility in short term period in Albanian market, being that the American dollar is considered a safe currency independently to the political context in the rest of the world. Furthermore, USD is the second foreign currency after Euro (according to financial and commercial transactions) and it is characterized by a peculiar probabilistic volatility distribution. In particular, USD volatility represents a continuous concern for economic agents exposed to the exchange risk. It follows that the measurement of the USD/ALL exchange rate volatility may help in the assessment and maintenance of capital needed for coverage purposes. The common financial time series dynamic models such as ARMA (1;1), ARCH (1) and GARCH (1;1) can be used to estimate the USD/ALL exchange rate volatility in short term period. Our results suggest that, in the presence of political factors as well as external shocks derived from country's main trade partners, the best way to estimate and forecast the USD/ALL exchange rate volatility in the short term is the use of the MS-GARCH model.
\end{abstract}

Keywords: financial time series dynamic models, exchange rate volatility forecasting.

\section{JEL classification: D51,D53, G17.}

\section{Introduction}

The present research aims to identify the functional form of USD/ALL exchange rate volatility in Albanian market in order to provide an econometric tool to economic agents exposed to the exchange risk, not only for short run forecasting, but also for the assessment and maintenance of economic capital for coverage purposes. Namely, looking at Fig.1 and Fig.2 in appendix, we can observe that USD/ALL exchange rate and its variance presents an interesting evolution over time that seems to follow some important economic and political events involving US and Albanian economies.

In particular, the Albanian currency has been significantly depreciated against USD in concomitance to:

- $\quad$ trade liberalization, implementation of flexible exchange rate regime and import volume growth of primary services and goods (1992);

- $\quad$ political/social issues followed consequently by the financial/economic instability (1997);

- $\quad$ the adoption of a common currency in the European Union (EURO) and the significant increase of imports and remittances from the EURO zone (2001-2002);

- $\quad$ Albania's economic slowdown in 2012-2014.

In particular, the period 2012-2014 is also characterized by the increase of Albanian exports toward US, China, Russia and South Korea and by the consequent increase of USD foreign demand (see Fig.3 in appendix). The USD/ALL first differences time series (Fig.4 in appendix) shows that the economic and political factors listed above are reflected in the trend of the USD/ALL exchange rate. In order to isolate the relationship between USD and ALL we need to use financial time series dynamic models. 
In particular, the following econometric analysis aims to test three different hypotheses on the dynamic model to be used. Such hypotheses are:

H1: The ARMA $(1 ; 1)$ model can accurately estimate USD/ALL exchange rate volatility in short term period;

$\mathrm{H} 2$ : The ARCH $(1 ; 1)$ model can accurately estimate USD/ALL exchange rate volatility in short term period;

H3: The GARCH $(1 ; 1)$ model can accurately estimate USD/ALL exchange rate volatility in short term period in the Albanian market.

Beside this introduction, the rest of the paper is organized as follows. Section 2 presents a brief literature review on financial time series modelling, Section 3 describes the empirical strategy adopted for our analyses, Section 4 provides the main results of our estimates, finally Section 5 concludes. Tables and figures are reported in appendix.

\section{Modelling institutional factors in time series analysis}

In general, the literature presents disputed empirical results regarding the impact of various institutional factors on exchange rates volatility. Many studies deal with exchange rate volatility modelling, although most of them are mainly focused on finding volatility sources for an appropriate market risk estimation and management (Marrison 2002). For this reason, empirical studies differ in the way they handle the exchange rate volatility issue. In particular, empirical literature on exchange rate volatility may be classified in two categories.

The first field of research is characterized by the use of different standard deviation errors' modifications in autoregressive or moving average models (AR and MA models), the second one is characterized by the use of models that treat autocorrelated errors attitude with varying variance, that is the so-called Autoregressive Conditional Heteroskedastic volatility models (ARCH).

The first field of research largely involves the use of ARMA (Autoregressive Moving Average) models, following Box et al. (2008) and Brooks (2002) methodologies. This field of literaturein general has the purpose to find the best specification (in statistical terms) that explains exchange rate volatility in order to forecast future values on the bases of past average values or past errors distribution, Examples are provided by Brooks (1997) and Hsieh (1989).

According to Engle (2001), Dowd (2002), Žiković (2008), Erdemlioglu et al. (2012) and Duffie and Pan (1997), ARMA models represent the best methodology in measuring exchange rate volatility or respective returns. In addition they provide the option of the largest loss expected calculation under a certain probability level during a given time period (depending on the exposure) for those entities that are exposed to a certain position and,consequently, are directly affected by exchange rate risk (Marcucci 2005).

The second field of research is characterized by the use of ARCH models, firstly introduced by Engle (1982) and Bollerslev (1986) and extended by Giot and Laurent (2001) and Orlowski (2004). Papers like Belke and Setzer (2003) can be classified in this field of literature and they study exchange rate volatility impact in labor market of Visegrad. Other examples are provided by Baum et al. (2004) that analyze the impact of exchange rate volatility on bilateral exports volume or by Sentana (1995) and Bali and Guirguis (2007) that use GARCH-type (Generalized Autoregressive Conditional Heteroskedasticity models) models in order to detect variance structural breaksdue to heteroskedasticity problems in the data analyzed.

\section{Empirical strategy and data}

Referring to USD/ALL exchange rate financial time series, from Fig. 4 and Fig. 5 in appendix it is apparent its heteroskedastic distribution. Consequently, we need to use financial time series dynamic models to estimate the USD/ALL exchange rate volatility and for forecasting in the short term. Dynamic models estimate the differential equations containing the stochastic component that is missing due to leptokurtic functional form that the financial time series in question presents.

Another important element observed in the USD/ALL exchange rate financial time series trend is the asymmetry of the distribution that confirms the possible presence of autocorrelation. 
In order to deal with the characteristics listed above, in general, two functional forms are used: autoregressive models (AR) and moving average models (MA). In addition, the Box-Jenkins (1970) methodology combines these models in order to obtain the extended ARMA (autoregressive moving average) models. This kind of models are used to describe the nonstationarity of a financial time series, however, in order to implement them in the time series in question, the trend component must be avoided. We use the logarithmic transformation in order to verify the short memory of USD/ALL exchange rate financial time series.

For our empirical analyses, we use the daily USD/ALL financial time series for the entire year 2013. In order to estimate the volatility of the daily USD/ALL exchange rate in the year 2013 we test the following hypotheses on the econometric model to be used.

H1: The ARMA (1;1) model can accurately estimate USD/ALL exchange rate volatility in short term period;

$\mathrm{H} 2$ : The ARCH $(1 ; 1)$ model can accurately estimate USD/ALL exchange rate volatility in short term period;

H3: The GARCH $(1 ; 1)$ model can accurately estimate USD/ALL exchange rate volatility in short term period in Albanian market.

The autoregressive process (AR) as can be understand from the name itself, relate the current values USD/ALL exchange rate financial time series data to the lagged values, through a linear autoregressive order and the AR order determines the entire model order thus, in these cases the model data explain better than anyone else itself. However, the AR models are not the only relation that can explain the behavior of the previously mentioned financial variables. Moving average (MA) models are also commonly used for this purpose. Thus, MA model is conceptually a linear regression of the current value of the series on a set of regressors that includes current and previous (unobserved) white noise error terms or random shocks. The random shocks at each point are assumed to be mutually independent and to come from the same distribution, typically a normal distribution, with zero mean and constant scale.

Meanwhile the mixed model ARMA admits that the financial time series are autoregressive and move averagely against variable and its residuals.

Estimates are conducted using the econometric software GRETL (1.9.8 version).

\section{Results}

Before to apply an ARMA model, the persistence of the autocorrelations should be estimated. As evidenced in Fig. 6, we can not confirm the first order autocorrelation of USD/ALL exchange rate data at $95 \%$ confidence level and the same situation persists to the residuals autocorrelation (Fig.7 and 8). By this way, it is not necessary to implement the ARMA model for the forecasting of USD/ALL exchange rate volatility because it can't estimate neither is volatility in short term period.

As a consequence, the hypothesis $\mathrm{H} 1$ can not be accepted at $95 \%$ confidence level. As further confirm, in order to prove the ARMA $(1 ; 1)$ model validity, we also perform econometric estimates (Table 1 in appendix) and look at residuals distribution to compare it to normal one. The results obtained demonstrate that the residuals are not normally distributed and do not fit with the actual ones (see Fig.9). As far as can be understand, ARMA $(1 ; 1)$ model residuals' are significantly distributed at the extreme values. The conclusion is that other models should be considered in order to accurately estimate and forecast USD/ALL exchange rate volatility in Albanian market.

As previously mentioned, the heteroskedasticity phenomenon refers to models' variables and residuals variance fluctuations against time. That's why its persistence in USD/ALL exchange rate financial time series data may negatively impact the exchange rate behavior itself by being transformed in its primarily risk. Thus, in order to take heteroskedasticity into account, other model categories should be used. Engle (1992) proposed to use ARCH (Autoregressive Conditional Heteroskedasticity models). As Engle (1992) assumed, in these kind of models the conditional variance is autoregressive and the residuals behavior is normal. Therefore, the conditional autoregressive heteroskedastic models simultaneously consider the equations of financial time series data conditional moving average as well as to the variance ones. Subsequently, it can be implemented ARCH (1) model by referring to $\mathrm{H} 2$ hypothesis of the study in order to estimate the USD/ALL volatility in short term period (estimation results in Table 2 in appendix). The results show that estimated point 
coefficients are all statistically significant at $95 \%$ confidence level. Regarding the specification test, the criterions of Akaike and Schwarz are not satisfied. As a consequence, the ARCH (1) model can not accurately estimate USD/ALL exchange rate volatility. It follows that we can not accept the $\mathrm{H} 2$ hypothesis of the study. The same conclusion are obtained examining residuals' full and partial autocorrelation as well as looking at normality test (Fig.10 and Fig. 11 in appendix), reconfirming the presence of heteroskedasticity in the financial time series in question. It follows that additional dynamic financial time series models should be considered.

The latter empirical studies pertaining to heteroskedastic autoregressive conditional variance proposed from Bollerslev (1986) have significantly improved the ones proposed from Engle (1992), introducing GARCH (Generalized Autoregressive Conditional Heteroskedasticity) models. The generalized autoregressive conditional heteroscedastic (GARCH) model is an extension of Engle's ARCH model for variance heteroscedasticity. If a series exhibits volatility clustering, this suggests that past variances might be predictive of the current variance. In particular, the $G A R C H(P, Q)$ model is an autoregressive moving average model for conditional variances, with P-GARCH coefficients associated with lagged variances, and QARCH coefficients associated with lagged squared innovations.

By other words, these kinds of models correspond to squared ARMA models. We test the validity of $\mathrm{H} 3$ hypothesis estimating a GARCH $(1 ; 1)$ model (results are reported in Table 3 in appendix). Two of the latest coefficients are statistically significant at $95 \%$ confidence level, but the specification tests ${ }^{1}$ results aren't reduce in confront of ARCH (1) model. On the other hand, the residuals' normality distribution results conduct to suppose an identical and symmetric data distribution. Consequently, we cannot reject the $\mathrm{H} 3$ hypothesis.

The estimation of the USD/ALL exchange rate volatility through GARCH $(1 ; 1)$ model demonstrates that the last one can accurately do it, but in any case, beyond the statistical estimations in order to confirm the acceptance of $\mathrm{H} 3$ hypothesis of the study the a/m model should be further implemented for the forecasting of financial time series in question in short term period. To this extent, we use moving window method for the short time period forecasting of USD/ALL exchange rate data (within a day period) for the entire year 2014 in correspondence of latest 252 exchange rate data pertaining to 2013. More specifically, the latest $252 \mathrm{USD} / \mathrm{ALL}$ exchange rate data will be used to forecast first USD/ALL exchange rate data of the year 2014 and so on. The USD/ALL exchange rate data forecasted through GARCH $(1 ; 1)$ model versus the current ones are presented in Fig. 12 in appendix. The forecasted data have exceeded the minimal established thresholds 51 times and never the maximal ( 13 breaches allowed). As a result, we can not accept the $\mathrm{H} 3$ hypothesis of the study. However, in order to be sure regarding the H3rejection we also explored the distribution of USD/ALL exchange rate financial time series without its trend component (see Fig.13 in appendix). The probabilistic distribution of the series in question demonstrates that it is necessary to specify the probabilistic distributions for different volatility regimes. Data (Fig. 13 and Fig. 14 in appendix) display high volatility periods, that is "path dependence regimes", in April, June, July, November and December 2014. Another detail observed in this financial time series is the casual USD/ALL exchange rates data which don't follow the autoregressive order of the also called "smooth structural breaks" (Fig.15 in appendix). According to Klaassen (2002) it is well known that in the presence of these structural breaks the GARCH $(1 ; 1)$ model can't accurately estimate USD/ALL exchange rate data and consequently forecast them.

\section{Final remarks}

The detailed analysis of USD/ALL exchange rate volatility in Albanian market demonstrated that no one of the models described as above is capable to estimate accurately its volatility. The forecasted data with GARCH $(1 ; 1)$ better perform with respect on the other two specifications. However the forecasted USD/ALL data exceeded the maximal threshold 51 times versus 13 breaches allowed at the $95 \%$ confidence level. The breaches due to "path dependence" and "smooth structural breaks" issues persistence in the USD/ALL exchange rate financial time series data mainly derived from political events in the country as well as in country's trade partnership corresponding to the external shocks.

\footnotetext{
1 The Akaike and Schwarz results estimated in the a/m models are used to diagnose whether the model fits with financial data behaviors and small values correspond to good indicators which further consist in a well adapted model.
} 
Correspondently, in order to analyze and forecast USD/ALL exchange rate it is necessary to use the Switching Regime Models since they are able to take into account "path dependence" and "smooth structural breaks" issues in financial time series data. However, before to use this econometric technique, it should be necessary to precisely identify the "structural breaks" from "internal financial time series data volatility regimes" as the first one is treated as a miss-autocorrelation data issue that can be identified through variance scale distribution analysis.

Hence, MS-GARCH models can still be useful in the exchange risk variance estimation and Value at Risk calculation until a certain time period with a reasonable confidence level. As a consequence, MS-GARCH models could still help investors in the estimation and maintenance of necessary economic capital to cover the potential exchange losses.

\section{References}

[1] Bali R., Guirguis H., (2007),"Extreme observations and non-normality in ARCH and GARCH", International Review of Economics \& Finance, n. 16, Issue 3, pp. 332-346.

[2] Baum, C. F., Caglayan, M., \& Ozkan, N., (2004)," Nonlinear effects of exchange rate volatility on the volume of bilateral exports", Journal of Applied Econometrics, 19(1), pp. 1-23.

[3] Belke, A., \& Setzer, R., (2003),"Exchange rate variability and labor market performance in the Visegrad countries", Economics of Planning, 36(2), pp. 153-175.

[4] Bollerslev, T.,(1986), “Generalized autoregressive conditional heteroskedasticity”, Journal of Econometrics, 31, pp. 307-327.

[5] Box, G.E.P. and Jenkins, G.M. (1970, 1976). Time Series Analysis: Forecasting and Control. San Francisco: Holden Day.

[6] Box, G.E.P., Jenkins, G.M. and Reinsel, G.C. (1994). Time Series Analysis: Forecasting and Control. Third Edition. Prentice Hall/Box, G.E.P. and Jenkins, G.M. (1970, 1976). Time Series Analysis: Forecasting and Control. San Francisco: Holden Day.

[7] Box, G. , Jenkins G.M. and Reinsel G.C. (2008). Time Series Analysis: Forecasting and Control. John Wiley and Sons, INC, New Jersey, 4th Ed., 6/2008, pp. 21-45.

[8] Brooks C., (1997), "Linear and non-linear (non-) forecastability of highfrequency exchange rates”, Journal of forecasting, n. 16, pp. 125-145.

[9] Brooks C. (2002).Introductory Econometrics for Finance, Chapter 2,5\&6, Cambridge University Press, Cambridge, 9/2002.

[10] Duffie, D. and Pan J., (1997), "An Overview of Value at Risk", Journal of Derivatives,V.4, pp. 7-49.

[11] Dowd, K., (2002). An introduction to market risk measurement, pp.3-33, John Wiley \& Sons Ltd, Chichester, 10/2002.

[12] Engle, R., (1982), "Autoregressive Conditional Heteroskedasticity with the Estimates of the Variance of United Kindom Inflation", Econometrica 50 (4): pp. 987-1007.

[13] Engle, R., Chowdhury, M. (1992), "Implied ARCH models from options prices, Journal of Econometrics. pp. 26-32.

[14] Engle, R., (2001), "GARCH 101: The use of ARCH/GARCH models in applied econometrics", Journal of economic perspectives, pp. 157-168.

[15] Erdemlioglu, D., Laurent, S., \& Neely, C., (2012)."Econometric modeling of exchange rate volatility and jumps", Federal Reserve Bank of St. Louis Working Papers 2012.

[16] Giot, P. and Laurent, S., (2001), "Modelling Daily Value-at-Risk Using Realized and ARCH-Type Models", Journal of Banking and Finance, 26, pp. 1273-1296. 
[17] Hsieh D. A., (1989),"Testing for nonlinear dependence in daily foreign exchange rates”, Journal of Business, Volume 62, pp. 329-68.

[18] Klaassen F (2002).Improving GARCH Volatility Forecast with Regime-Switching GARCH.Empirical Economics, 27(2), 363-394.

[19] Marrison C., (2002). The Fundamentals of Risk Measurement, Chapter 5, McGraw Hill, New York, 6/2002.

[20] Marcucci, J., (2005),"Forecasting Stock Market Volatility with Regime- Switching GARCH Models", Studies in Nonlinear Dynamics and Econometrics, 9(4), pp. 1-53.

[21] Orlowski, L. T., (2004)," Exchange rate risk and convergence to the euro (No. B 25-. 2004)",ZEl working paper.

[22] Sentana E., (1995), "Quadratic ARCH models: a potential re-interpretation of ARCH models", Review of Eonomic Studies, n. 62, pp. 639-661.

[23] Zakoïan J., (1994), "Threshold Heteroskedasticity Models", Journal of Economic Dynamics and Control, 15, pp. 931 955.

[24] Žiković, S., (2008), “Calculating VaR in EU Candidate States”, South East European Journal of Economics and Business, 3(1), pp. 23-33.

\section{APPENDIX}

Figure 7 - The USD/ALL exchange rate trend during 2013

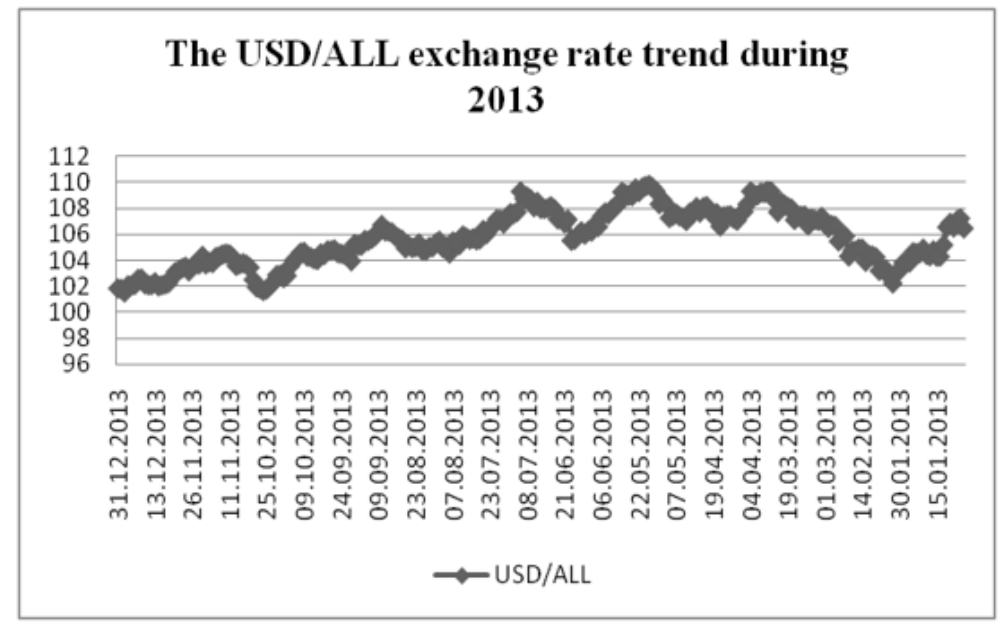

Source: Bank of Albania data, authors' elaboration. 
Figure 8 - The USD/ALL exchange rate variance trend during 2013

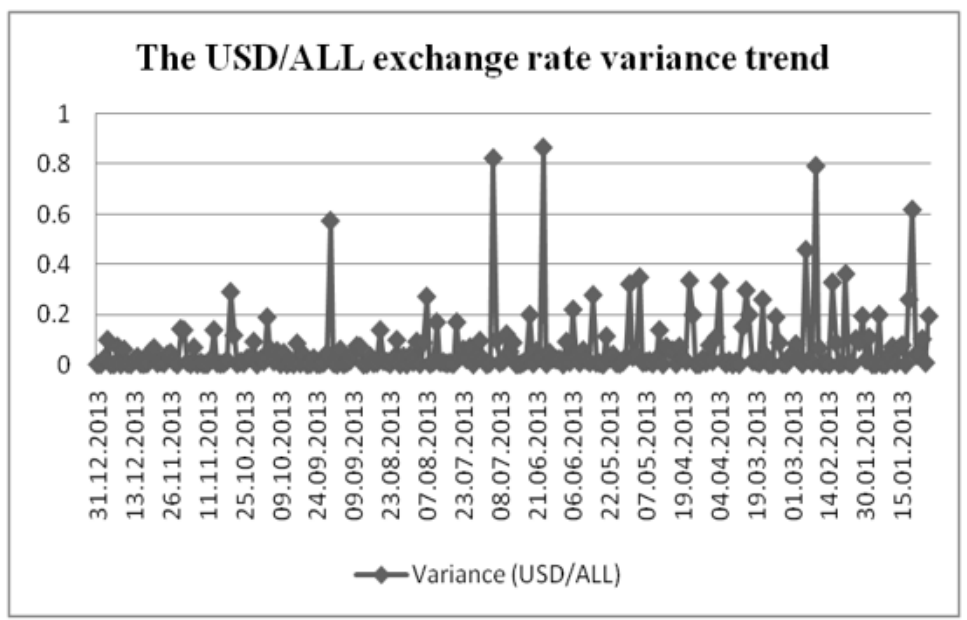

Source: Bank of Albania data, authors' elaboration

Figure 3 - Albanian exports trend toward USD-zone (US, Russia, China and South Korea)

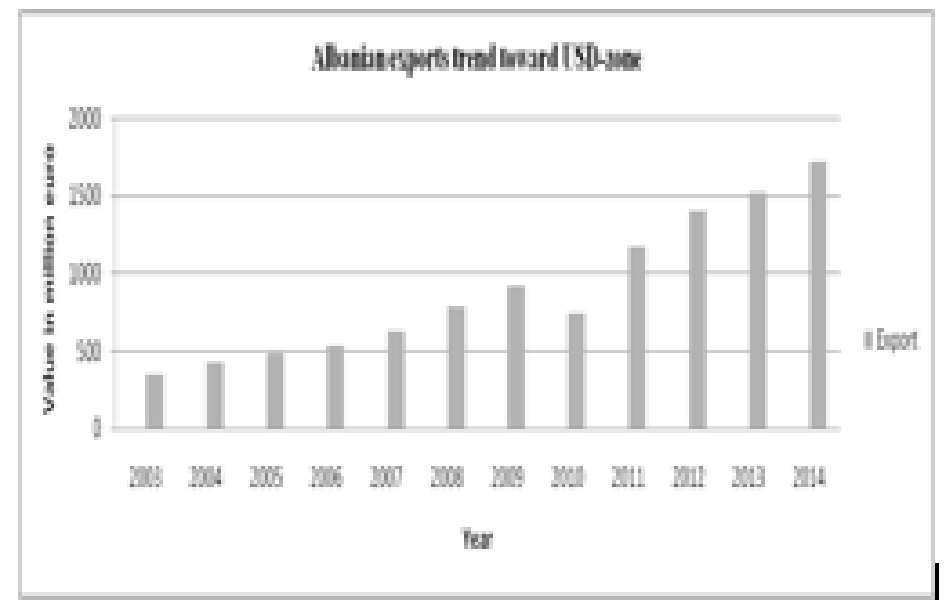

Source: Bank of Albania data, authors' elaboration. 
Figure 4 - The USD/ALL exchange rate first differences trend during 2013

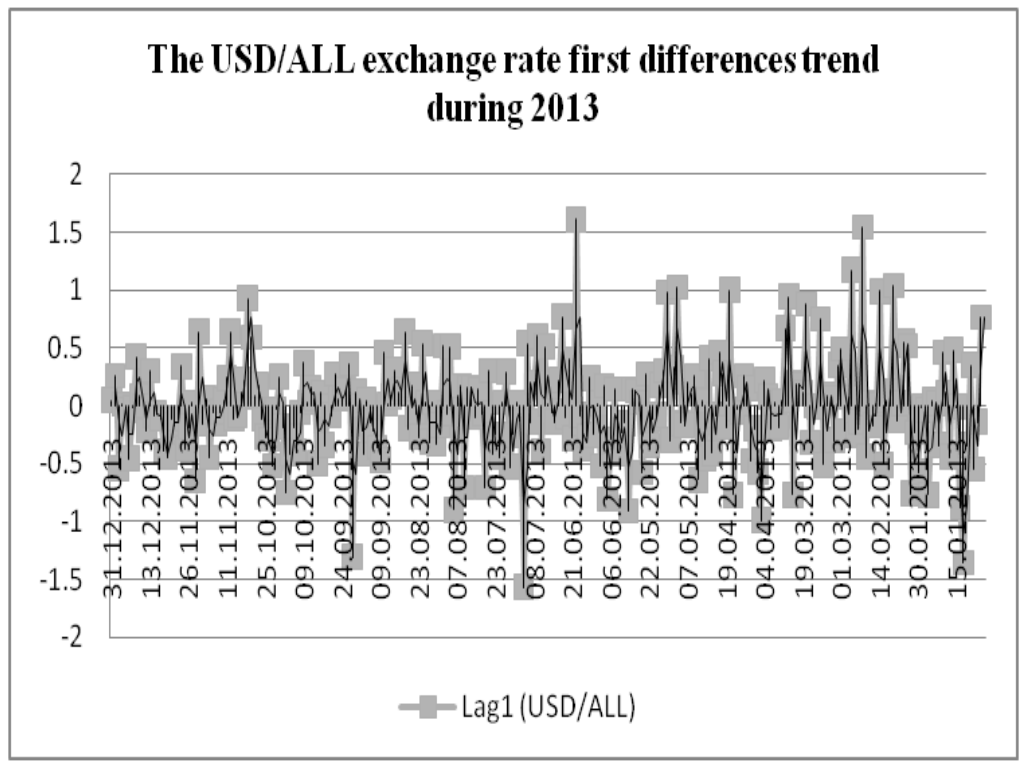

Source: Bank of Albania data, authors' elaboration.

Figure 5 - Lack of stochastic component in the USD/ALL exchange rate trend during 2013

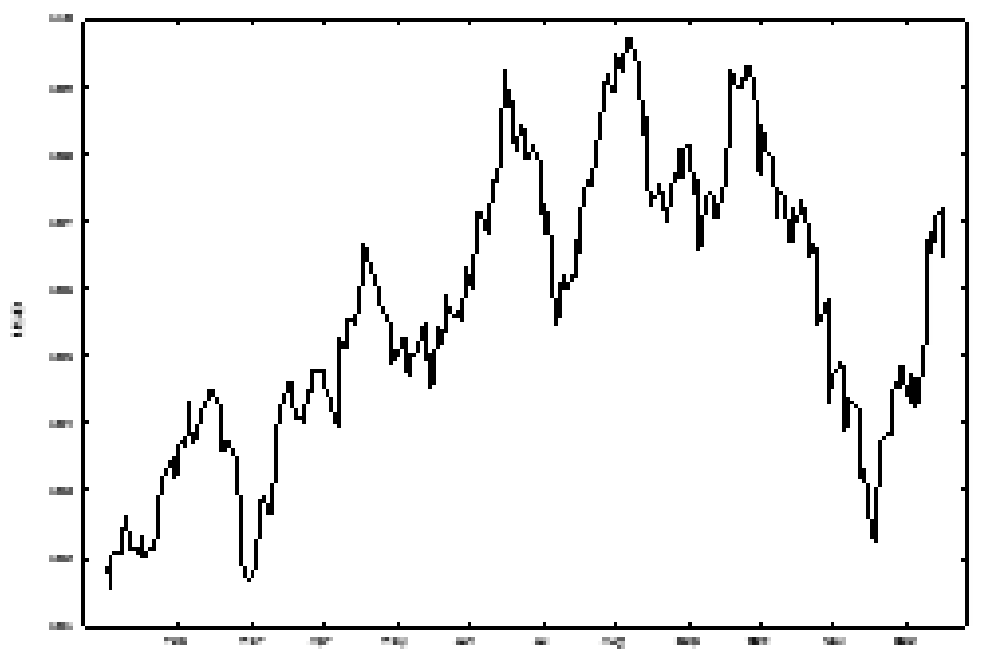

Source: Bank of Albania data, authors' elaboration. 
Figure 9 - The USD/ALL exchange rate correlogram
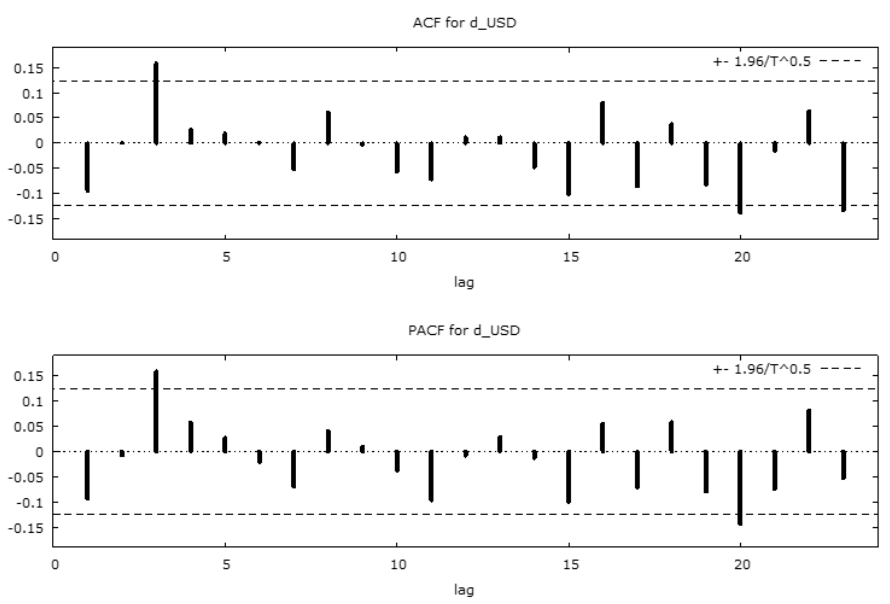

Bank of Albania data, authors' elaboration.

Figure 10 - The ARMA (1;1) model residuals correlogram results
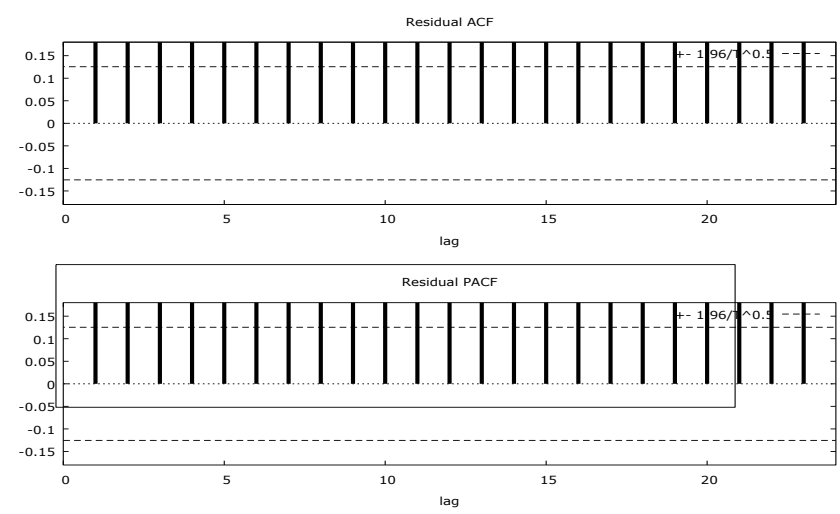

Source: Bank of Albania data, authors' elaboration. 
Figure 11 - The ARMA (1;1) model residuals' normality test results
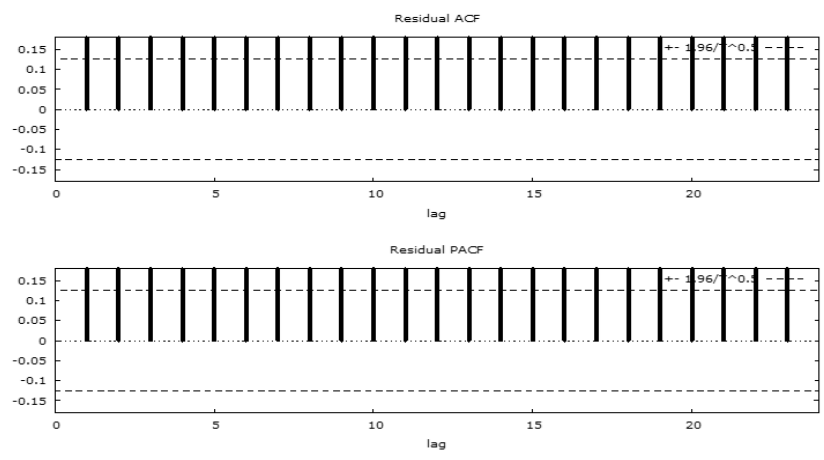

Source: Bank of Albania data, authors' elaboration.

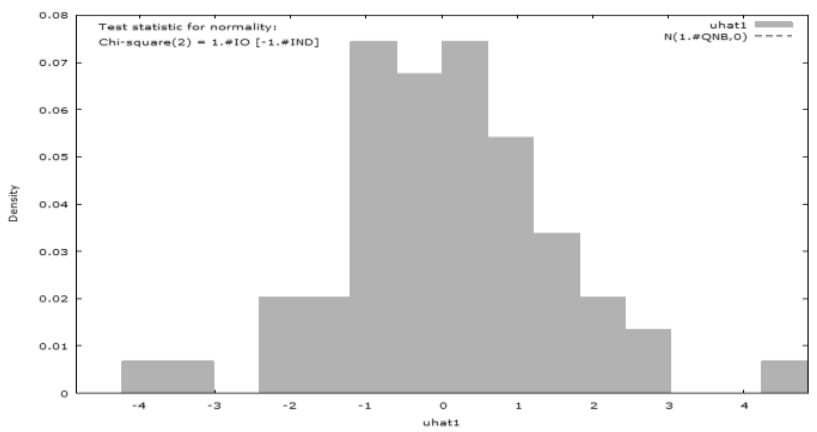

Figure 12 - The ARMA (1;1) residuals' versus actual ones

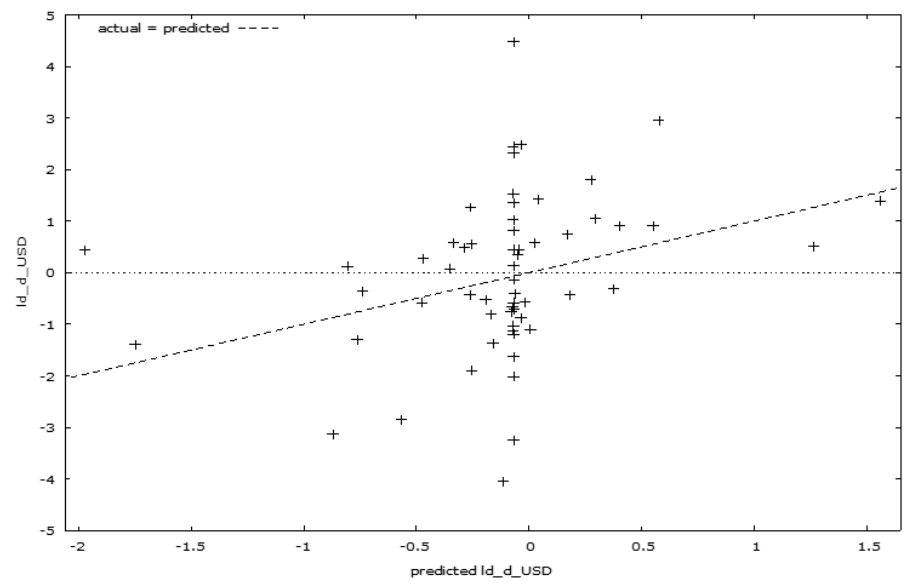




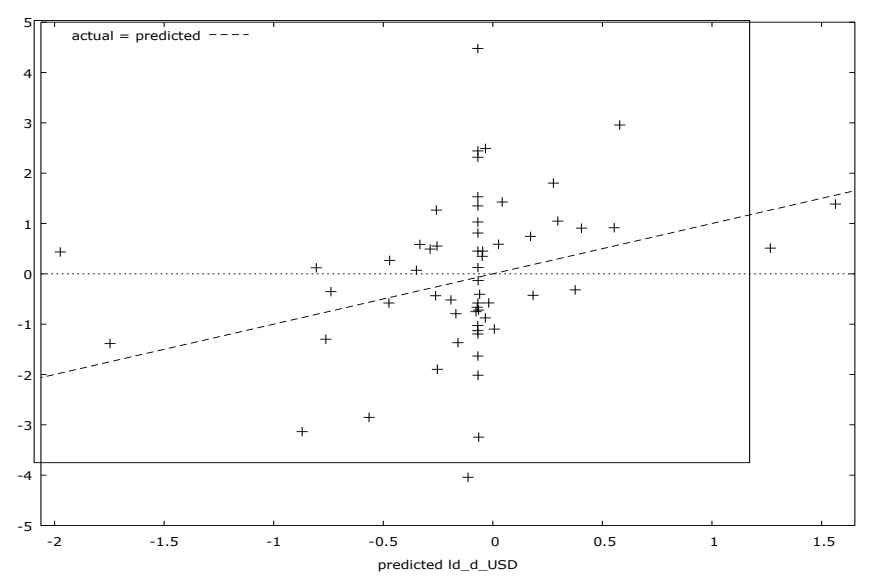

Source: Bank of Albania data, authors' elaboration.

Figure 13 - The $A R C H(1)$ residuals full and partial autocorrelation data

Residual ACF

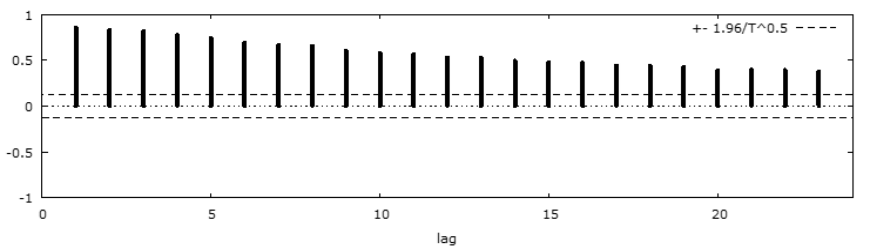

Residual PACF

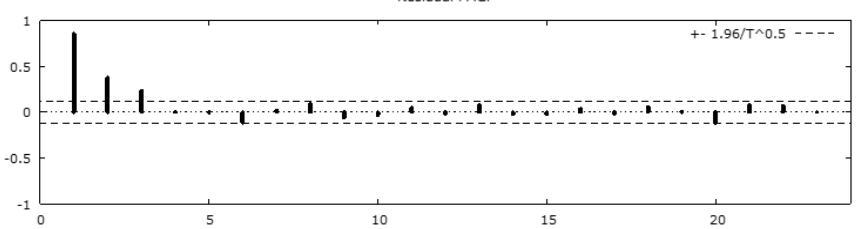




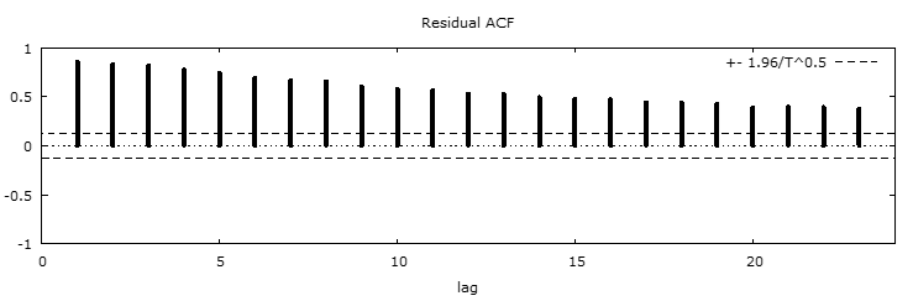

Residual PACF

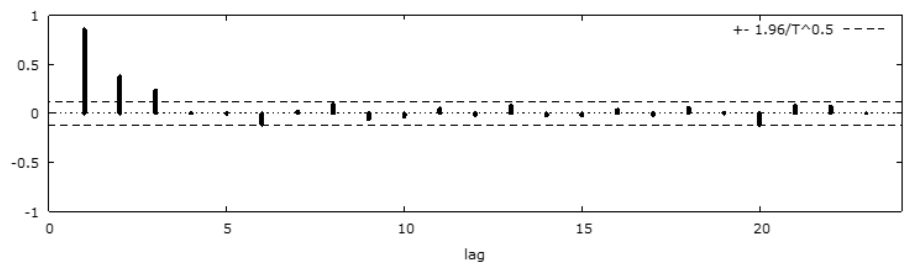

Source: Bank of Albania data, authors' elaboration.

Figure 14 - The $A R C H(1)$ residuals quantiles distribution

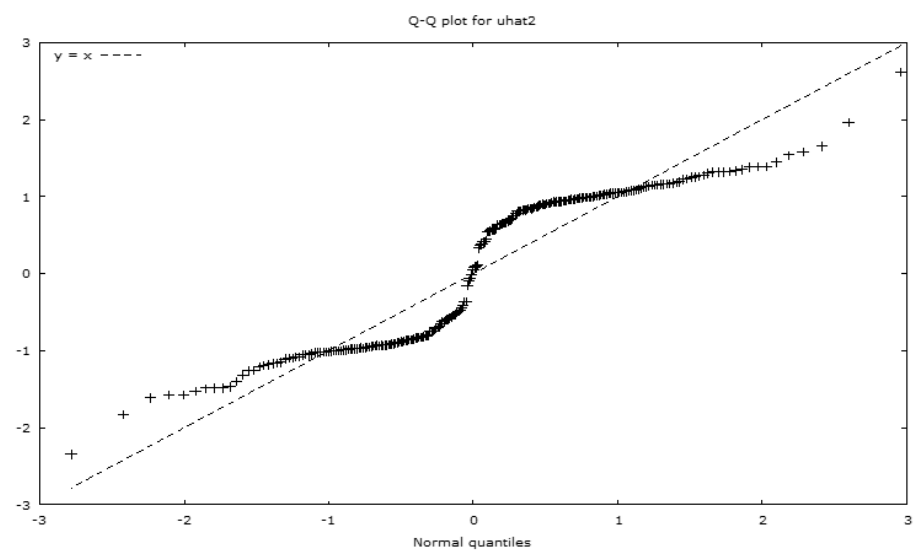

Source: Bank of Albania data, authors' elaboration. 
Figure 15 - The USD/ALL exchange rate forecasted data through $\operatorname{GARCH}(1 ; 1)$

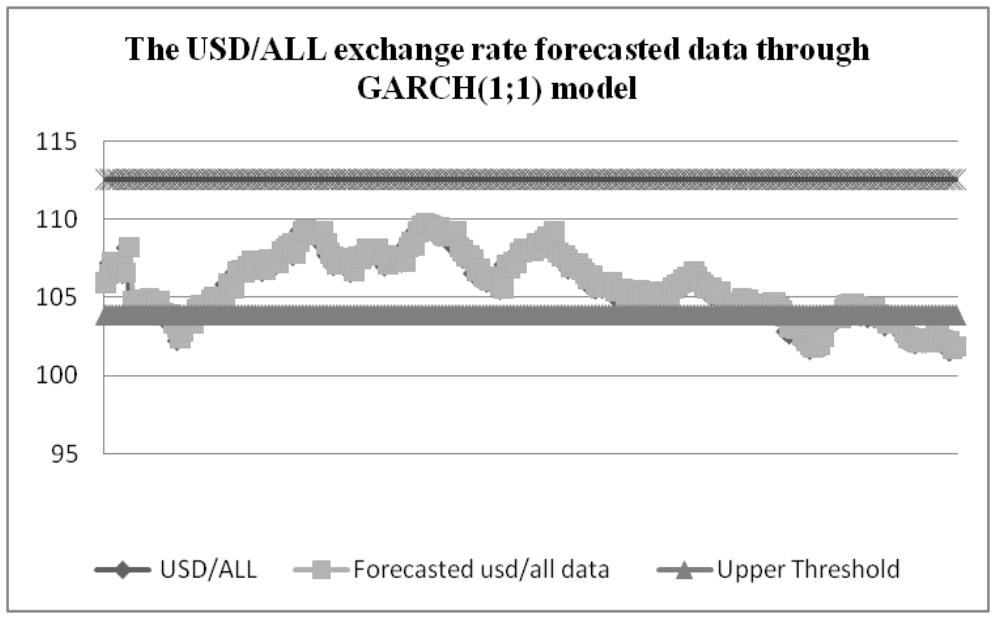

Source: Bank of Albania data, authors' elaboration.

Figure 16 - The distribution of USD/ALL exchange rate data without its trend component

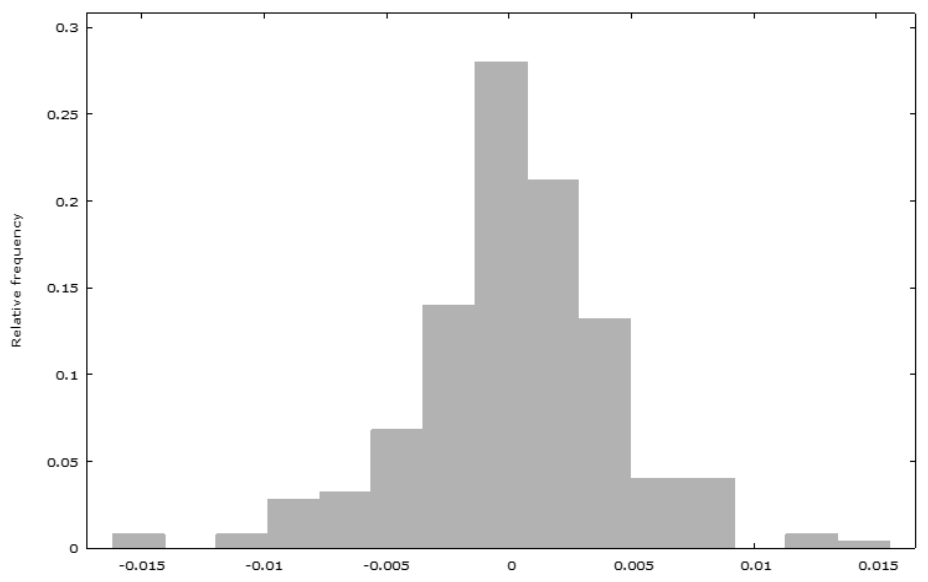

Source: Bank of Albania data, authors' elaboration. 
Figure 17 - The distribution of USD/ALL exchange rate data regimes

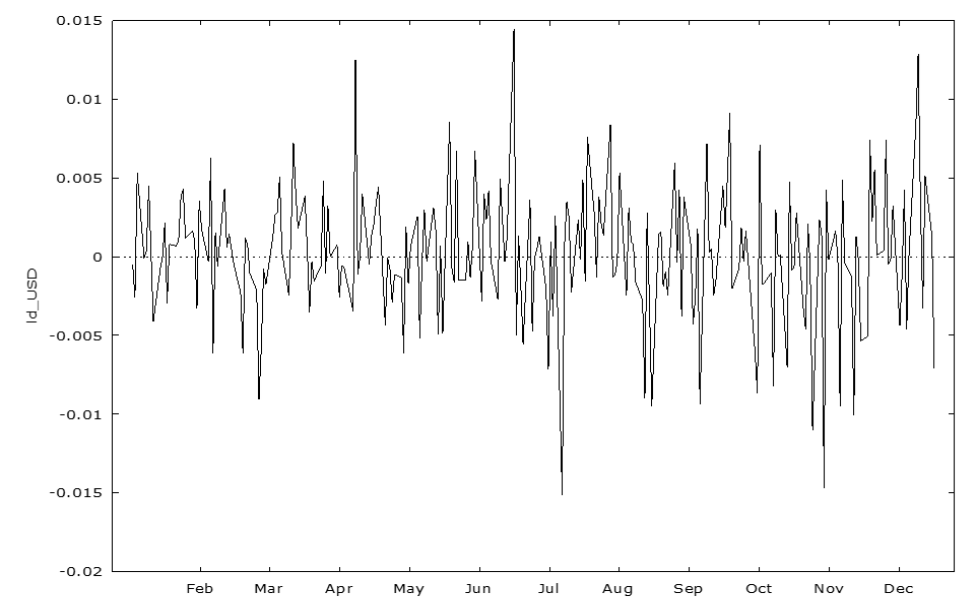

Source: Bank of Albania data, authors' elaboration.

Figure 18 - The scaled frequency of USD/ALL exchange rate data

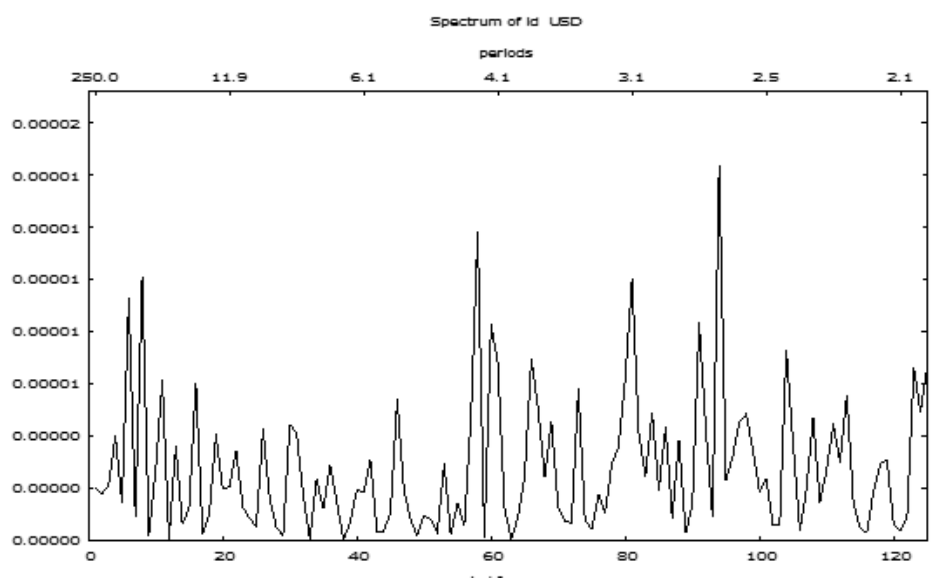

Source: Bank of Albania data, authors' elaboration. 
Table 1 - ARMA $(1 ; 1)$ model estimates - Authors' elaboration using GRETL

Model 1: ARMA, using observations 2013/01/03-2013/12/31 ( $T=252)$

Missing or incomplete observations dropped: 185

Dependent variable: Id_d_USD/ALL

Standard errors based on Hessian

$\begin{array}{lllll} & \text { Coefficient } & \text { Std. Error } & z & p \text {-value } \\ \text { const } & -0.0681016 & 0.11779 & -0.5782 & 0.56315 \\ \text { phi_1 } & 0.350996 & 0.330744 & 1.0612 & 0.28858 \\ \text { theta_1 } & -0.905027 & 0.335709 & -2.6959 & 0.00702(* *)\end{array}$

$\begin{array}{ll}\text { Mean dependent var } & -0.026374 \\ \text { Mean of innovations } & 0.090511 \\ \text { Log-likelihood } & -104.8236 \\ \text { Schwarz criterion } & 225.9574\end{array}$

AR

Root 1

2.8490

0.0000

2.8490

0.0000

MA

Root 1

1.1049

0.0000

1.1049

0.0000

Test for normality of residual -

Null hypothesis: error is normally distributed

Test statistic: Chi-square(2) = 1.\#INF

with $p$-value $=-1$.\#IND

\section{Table 2 - ARCH(1) model estimates - Authors' elaboration using GRETL}

Model 2: ARCH, using observations 2013/01/03-2013/12/31(T = 252)

Dependent variable: Id_d_USD/ALL

Standard errors based on Hessian

$\begin{array}{lllll} & \text { Coefficient } & \text { Std. Error } & z & p \text {-value } \\ \text { const } & 105.342 & 0.220175 & 478.4448 & <0.00001\left({ }^{* \star *}\right) \\ \text { alpha(0) } & 0.176721 & 0.0796777 & 2.2179 & 0.02656\left({ }^{* *}\right) \\ \text { alpha(1) } & 0.983003 & 0.124065 & 7.9233 & <0.00001\left({ }^{* * *}\right)\end{array}$




$\begin{array}{llll}\text { Mean dependent var } & 105.6884 & \text { S.D. dependent var } & 2.108586 \\ \text { Log-likelihood } & -465.8988 & \text { Akaike criterion } & 939.7976 \\ \text { Schwarz criterion } & 953.8994 & \text { Hannan-Quinn } & 945.4725\end{array}$

Unconditional error variance $=10.397$

Table 3 - GARCH(1;1) model estimates - Authors' elaboration using GRETL

Model 3: GARCH, using observations 2013/01/03-2013/12/31 ( $T=252)$

Dependent variable: Id_d_USD/ALL

Standard errors based on Hessian

$\begin{array}{lllll} & \text { Coefficient } & \text { Std. Error } & z & p \text {-value } \\ \text { alpha(0) } & 283.347 & 24457.1 & 0.0116 & 0.0076 \\ \text { alpha(1) } & 0.926364 & 9.01156 & 0.1028 & 0.04812 \\ \text { beta(1) } & 0.0483497 & 9.2615 & 0.0052 & 0.99583\end{array}$

Mean dependent var $\quad 105.6884$

S.D. dependent var $\quad 2.108586$

Log-likelihood

$-1525.894$

Akaike criterion

3059.787

Schwarz criterion

3073.889

Hannan-Quinn

3065.462

Unconditional error variance $=11205.7$ 